\title{
The Association of Physical Function Measures With Frailty, Falls History, and Metabolic Syndrome in a Population With Complex Obesity
}

\author{
Amanda Rhynehart ${ }^{1 *}$, Colin Dunlevy ${ }^{1}$, Katie Hayes ${ }^{1}$, Jean O'Connell ${ }^{1,2}$, Donal O'Shea ${ }^{1,2}$ \\ and Emer O'Malley' \\ ${ }^{1}$ Weight Management Service, St Columcille's Hospital, Dublin, Ireland, ${ }^{2}$ Obesity Research Group, St Vincent's University \\ Hospital, Dublin, Ireland
}

OPEN ACCESS

Edited by:

Alberto Falchetti,

Istituto Auxologico Italiano (IRCCS), Italy

Reviewed by: Katharina Kerschan-Schindl, Medical University of Vienna, Austria

Paolo Capodaglio,

University of Turin, Italy

*Correspondence:

Amanda Rhynehart

amanda.rhynehar@gmail.com amanda.rhynehart@hse.ie

Specialty section:

This article was submitted to Medical and Surgical Rehabilitation,

a section of the journal

Frontiers in Rehabilitation Sciences

Received: 28 May 2021

Accepted: 16 July 2021 Published: 16 September 2021

Citation:

Rhynehart A, Dunlevy C, Hayes $K$ O'Connell J, O'Shea D and O'Malley E (2021) The Association of Physical Function Measures With Frailty, Falls History, and Metabolic Syndrome in a Population With Complex Obesity. Front. Rehabilit. Sci. 2:716392. doi: 10.3389/fresc.2021.716392
Background: Frailty, falls and metabolic syndrome are known to be associated with poorer physical function. This study builds on available research by further investigating the relationship between physical function measures, including those comprising frailty, with metabolic syndrome (MetS) and falls, in the context of complex obesity.

Methods: Participants were recruited from the national Level 3 weight management service in Ireland. A retrospective audit of data gathered at initial assessment was performed. Data included past medical history, blood tests, blood pressure measurement, anthropometrics, falls history, self-reported physical activity levels (PALS) and physical function measures, including hand grip strength (HGS), "timed up and go" (TUG), functional reach (FR), sit to stand (STS) and gait speed. A modified version of the Fried Frailty Index was employed.

Results: Of the 713 participants, 65.1\% $(n=464)$ were female and 34.9\% $(n=249)$ were male with a mean age of $44.2( \pm 11.7)$ years and body mass index (BMI) of 50.6 $\mathrm{kg} / \mathrm{m}^{2}( \pm 8.2)$. Frailty was identified in $3.4 \%(n=24)$, falls in $28.8 \%(n=205)$ and MetS in $55.1 \%(n=393)$. Frailty was associated with older age $(53.8 \pm 14.3$ vs. $43.9 \pm 11.5$ years), poorer PALs ( $27.29 \pm 46.3$ vs. $101.1 \pm 147.4 \mathrm{~min} / \mathrm{wk})$, reduced grip strength $(17.7 \pm 4.6$ vs. $34.2 \pm 11.0 \mathrm{Kg})$ longer STS $(21.7 \pm 6.6$ vs. $13.7 \pm 5.7 \mathrm{~s})$, shorter functional reach $(29.7 \pm 7.9$ vs. $37.9 \pm 8.2 \mathrm{~cm})$ and slower gait speed $(0.6 \pm 0.2 \mathrm{vs} .1 .1 \pm$ $0.5 \mathrm{~m} / \mathrm{s})$. Those reporting a falls history had a reduced FR $(35.8 \pm 8.9 \mathrm{vs} .38 .3 \pm 7.8 \mathrm{~cm})$ and slower STS (15.4 \pm 8.0 vs. $13.3 \pm 4.7 \mathrm{~s})$. Participants with MetS had lower PALs $(83.2 \pm 128.2$ vs. $119.2 \pm 157.6)$ and gait speed $(1.1 \pm 0.3$ vs. $1.2 \pm 0.7 \mathrm{~m} / \mathrm{s})$. There was no difference in BMl between fallers and non-fallers (51.34 \pm 8.44 vs. $50.33 \pm 8.13$ $\left.\mathrm{Kg} / \mathrm{m}^{2}, p=0.138\right)$, nor between those with or without MetS. Significant associations were found between BMl and all physical function measures except the TUAG.

Conclusion: The associations between frailty, falls and MetS and their combined impact on physical function in people living with obesity demonstrates the need for appropriate screening. Utilising grip strength and gait speed to identify frailty in those with obesity and metabolic syndrome could help target therapies aimed at improving strength, physical function and ultimately quality of life.

Keywords: physical function, frailty, falls, falls history, metabolic syndrome, obesity, complex obesity 


\section{INTRODUCTION}

Frailty is a multidimensional concept that is primarily associated with an age-related decline in functional capacity. It has significant implications for an individual's response to stressors (1) including falls. Frailty is linked to poorer health outcomes in older adults (2) and is a risk factor for both single and recurrent falls in those 50 years and over (3). The development of frailty has been associated with both chronic obesity and the development of obesity in late adulthood (4). The Fried Frailty Index (FFI) is the most cited frailty screening tool (5). It is composed of five criteria, including unintentional weight loss, self-reported exhaustion, reduced strength, slow walking speed, and low physical activity.

The Irish Health Service Executive and the World Health Organisation (WHO) state over 1 quarter of communitydwelling adults over 65 years report falling at least once each year (6), while data from the Irish Longitudinal study on Ageing (TILDA) reports falls in a third of Irish adults aged 65 years and over (7). The WHO state that falls are associated with a significant economic burden (8) with between 0.85 and $1.5 \%$ of total healthcare expenditure devoted to their management (9). While falls are often considered a problem for older populations, Peeters et al., analysing data from across four population-based cohort studies, highlighted a sharp increase in prevalence of falls in middle-age, suggesting that falls are not just a problem of old age (10). This is also born out in The Irish Longitudinal Study on Ageing (TILDA) report 2019 (7).

Reduced muscle function and abdominal obesity have been associated with metabolic syndrome in older adults (11), which in turn has been associated with falls in this age group $(12,13)$. There is little data however, on the relationship between muscle function and abdominal obesity in younger adults, or those living with obesity, despite the prevalence of metabolic syndrome in obesity. The association between muscle function, falls has been highlighted primarily as an age-related muscle strength problem (14). However, recent research among people living with obesity has identified an increased risk of falls among this population across age groups $(6,15,16)$. As noted in these studies, many questions remain unanswered regarding the impact of obesity on functional capacity in younger adults. The concurrent presence of metabolic syndrome may present an additional mediating factor in this impact.

Obesity is recognised as a complex multifactorial disease affecting a range of body systems. The impact of the chronic lowgrade, systemic inflammatory process in obesity on metabolic regulation is well-documented (17), as is reduced physical function in those with obesity (18). Decreased muscle function has been associated with metabolic syndrome across age groups (19) which is a component of falls risk, and frailty.

In recent decades, the need for assessment and timely diagnosis of weight-related metabolic complications in younger adults and adolescents has been recognised (20, 21). However, the same attention is not given to the assessment of frailty and its composite measures in younger people living with obesity. Given the association with metabolic syndrome, frailty may be underdiagnosed in this group. It is possible that frailty is underdiagnosed in younger people with obesity. Identifying the

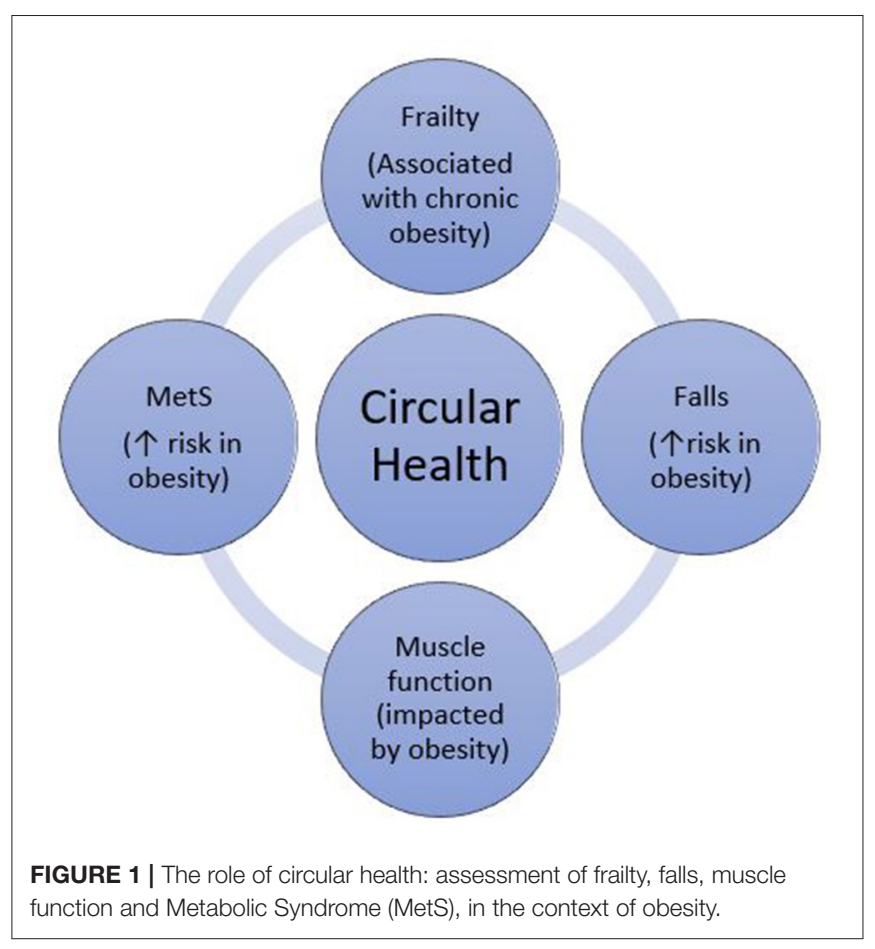

presence of frailty is challenging given its multifactorial nature, however measures of physical function are useful in assessing both frailty and falls risk. Although no one frailty measure has been agreed upon, the Fried Frailty phenotype measure has been extensively used, with gait speed and grip strength combined being used as a proxy measure to determine frailty in primary care (1). Population-specific reference ranges are used to identify natural variance in physical function, for example in age and gender. These provide helpful guidance in relation to identifying at-risk groups. Comparisons between populations with and without obesity, across similar age and gender cohorts, serves to contextualise these measures and inform risk identification in people with obesity.

The concept of circular health (Figure 1) refers to the key role of an interdisciplinary approach in identifying and treating the multifactorial determinants of ill health. While specialist treatment of complex obesity involves assessment and treatment of both metabolic and physical function parameters (22), there is little guidance on how these assessments should inform each other. Given the interplay between metabolic syndrome, muscle function, falls and frailty, each of these should be considered in the assessment and management of the others. These interactions may be overlooked in this population, highlighting the importance of a circular health perspective when treating complex obesity.

\section{AIMS}

This study aims to build on available research into metabolic syndrome, frailty, and falls, by further investigating the relationship between physical function measures, including those 
comprising frailty, with metabolic syndrome and falls, in the context of complex obesity of Grade 3 and above.

\section{METHODS}

A comprehensive multidisciplinary assessment is performed for all patients attending the national Level 3 weight management service (WMS) in Ireland. The WMS delivers a yearlong programme of MDT treatment with medical, nursing, physiotherapy, dietetics and psychology input, including assessment for bariatric surgery. The WMS accepts referrals for adults (aged 18 years and above) with complex obesity from primary and secondary care providers. A retrospective audit of data gathered at initial assessments was performed. Patients attending the WMS record consent for utilisation of personal and medical data for research purposes as approved by the St. Vincent's University Healthcare Group Ethics and Medical Research Committee. Data included blood pressure, triglycerides, HDL cholesterol, fasting blood glucose, past medical history, anthropometric measurements, falls history, self-reported physical activity levels (PALs), physical function measures, including hand grip strength (HGS), "timed up and go" (TUG), functional reach and gait speed. Weight $(\mathrm{Kg})$ and height $(\mathrm{m})$ were measured on a Seca digital scales and stadiometer and body mass index (BMI) in $\mathrm{Kg} / \mathrm{m}^{2}$ was calculated. Blood pressure was measured using an extra-large automated cuff (Omron HEM-907XL).

For this study, a modified version of the Fried Frailty Index was employed, utilising grip strength in conjunction with gait speed. This dual criteria measure for predicting the Fried Frailty phenotype has been shown to be accurate, with positive predictive value of $87.5 \%$ (1). A cut-off value of $0.9 \mathrm{~m} / \mathrm{s}$ in walking speed and $28 \mathrm{~kg}$ in grip strength for men, and a corresponding value of $0.8 \mathrm{~m} / \mathrm{s}$ and $18 \mathrm{~kg}$ for women were used (23). Those below the cut off point for both measures were categorised as frail.

Fallers were categorised as those who had fallen at least once in the preceding year. Physical activity levels were recorded as minutes per week. HGS was measured using a hand-held dynamometer with the upper limb in a neutral position and the elbow flexed to 90 degrees (Jamar ${ }^{\circledR}$, Patterson Medical, Warrenville, IL, USA) in accordance with the recommendations of the American Society of Hand Therapists Hand Dynamometer (24) and was recorded in kilogrammes. The TUG was recorded as the time taken for an individual to stand up, walk $3 \mathrm{~m}$ turn and return to sitting (25). Functional reach, whereby the distance between an initial starting position and maximal forward reach was measured in $\mathrm{cm}$. In standing, participants were asked to raise their arm to $90^{\circ}$ of shoulder flexion and to reach forward in the same plane to a maximal forward reach finishing position.

The International Diabetes Federation (IDF) categorises metabolic syndrome as having central obesity and two of the following: raised triglycerides $(\geq 1.7 \mathrm{mmol} / \mathrm{L})$, reduced $\mathrm{HDL}$ cholesterol $(\leq 1.03 \mathrm{mmol} / \mathrm{L}$ for men or $\leq 1.29 \mathrm{mmol} / \mathrm{L}$ for women), raised fasting plasma glucose ( $\mathrm{HbAl} \mathrm{c} \geq 38 \mathrm{mmol} / \mathrm{mol}$ ) or Type 2 diabetes and hypertension (systolic $\mathrm{BP} \geq 130 \mathrm{~mm} \mathrm{Hg}$ ) (26). Those meeting two or more of type the above criteria with a
BMI $\geq 30 \mathrm{~kg} / \mathrm{m}^{2}$ were categorised as having metabolic syndrome. Waist circumference measurement is often not feasible in this population due to the presence of a panus or apron and is not recommended in those with a BMI over $35 \mathrm{~kg} / \mathrm{m}^{2}$ (27), and so is not routinely measured at initial WMS assessment. This BMI cut-off was used as it incurs increased cardio-metabolic risk comparable to waist circumference in line with the ICCR consensus statement (28).

Differences in physical function measures were assessed across gender and between fallers and non-fallers and those with and without metabolic syndrome and those with and without frailty using Mann-Whitney tests. Correlations between continuous variables were assessed using Spearman's Rank Correlation Coefficient. To further investigate the relationship between physical function measures, frailty and metabolic syndrome, patients were grouped into three groups: those with both frailty and metabolic syndrome, those with only one of these conditions, and those with neither. Differences in the physical function measures not included in the frailty measure were compared via analysis of variance using Kruskal-Wallis tests with post-hoc analysis of significant results.

Values of $P<0.05$ were considered significant. Statistical Package for Social Science (IBM SPSS) (SPSS, Inc., Chicago, Illinois) was used for all statistical analysis. Participants were excluded due to missing data on physical function measures, falls, or metabolic syndrome.

\section{RESULTS}

\section{Demographics}

Data on 713 WMS patients was analysed. The majority were female (female $n=464,65.1 \%$ vs. male $n=249,34.9 \%$ ). Mean age was $44.2 \pm 11.7$ years, with men slightly older than women ( 45.3 vs. 43.6 years, $p=0.05$ ). Mean BMI was $50.62 \pm 8.23 \mathrm{~kg} / \mathrm{m}^{2}$, median $53.6 \mathrm{~kg} / \mathrm{m}^{2}$ ranging from 30.6 to $92.0 \mathrm{~kg} / \mathrm{m}^{2}$. Fallers accounted for $28.8 \%(n=205)$, with $71.2 \%(n=508)$ non-fallers.

\section{Comparisons}

Normality of distribution was assessed using Shapiro-Wilk test for age, BMI and physical function measures. All were found not to be normally distributed. There was no significant difference in BMI, falls history or frailty between genders.

Frailty was identified in $3.4 \%(n=24)$ patients, with no significant difference between genders. Frail patients were significantly older $(53.8 \pm 14.3$ vs. $43.9 \pm 11.5$ years, $p=0.00)$, had lower PALs $(27.29 \pm 46.3$ vs. $101.1 \pm 147.4 \mathrm{~min} / \mathrm{wk}, p=$ $0.003)$, slower TUG (12.43 \pm 4.1 vs. $8.5 \pm 14.6 \mathrm{~s}, p=0.00)$, and took longer to sit to stand $(21.7 \pm 6.5$ vs. $13.7 \pm 5.7 \mathrm{~s}, p=0.00)$, and had a shorter functional reach $(29.7 \pm 7.9$ vs. $37.9 \pm 8.2 \mathrm{~cm}$, $p=0.00$ ). Frailty was associated with falls, with falls significantly more common in those categorised as frail, ( $50 \%$ fallers in frail vs. $28 \%$ fallers in "not frail," Pearson Chi Square $p=0.024$ ). Frailty was not associated with presence of metabolic syndrome.

There was no difference in BMI between fallers and non-fallers nor between those with or without metabolic syndrome.

Metabolic syndrome was present in $55.1 \%(n=393)$ of patients with no significant difference between genders. There 
was no difference in the prevalence of metabolic syndrome among fallers (59.5\%) compared to non-fallers (53.3\%).

Significant correlations were noted between BMI and all physical function measures: self-reported PALs $(p=0.000)$, grip strength $(p<0.05)$, TUAG $(p=0.00)$, functional reach $(p=$ $0.001)$, sit to stand $(p<0.01)$, and gait speed $(p=0.000)$.

Differences in PALs and physical function between genders, fallers and non-fallers, and those with and without metabolic syndrome, and with and without frailty are shown in Table 1. Normality and equality of variance were assessed using Levene's test, and Shapiro-Wilk test. These assumptions were not met, so Kruskall-Wallis test was used to assess physical function measures across the Metabolic Syndrome/Frail groups. All physical function measures [grip strength $(p=0.00)$, TUAG $(p$ $=0.00)$, functional reach $(p=0.00)$, Sit to Stand $(p=0.00)$, and gait speed $(p=0.00)$ ] were significantly poorer in those with both frailty and metabolic syndrome and in those with only one condition, compared to those with neither. PALs did not vary significantly across the groups.

\section{DISCUSSION}

This study showed associations between physical function and BMI. We found that functional reach and sit to stand measures were poorer in patients with frailty or a history of falls, and that these differences were additive, with significantly poorer functional reach and sit to stand performance in those with both frailty and metabolic syndrome compared to those with only one condition, or neither.

Published data on the Irish longitudinal study on ageing (TILDA) population, a nationally representative sample of community-dwelling adults aged 50 years and above living in the Republic of Ireland, reports prevalence of physical frailty in Ireland increasing with advancing age: $11 \%$ in those aged $55+$; $15 \%$ in $65+; 19 \%$ in $70+; 25 \%$ in $75+; 35 \%$ in $80+$ and $46 \%$ in $85+(3)$. Frailty in this younger population with obesity was markedly less at $3.4 \%$, which is lower than even the $8.6 \%$ reported from the Canadian Health Measures Study data estimates of frailty in adults 18-79 years old (29). A prevalence of frailty based on the Fried criteria was $6.5 \%$ in a Canadian study of older community dwelling adults (1).

The complete FFI classifies physical frailty status by the presence in an individual of five criteria, namely exhaustion/fatigue, unintended weight loss, slow walking speed, reduced muscle strength and low levels of physical activity. The presence of none, $1-2$ and $\geq 3$ of these criteria indicates that an individual is non-frail, pre-frail or frail, respectively (30). Hence, the classification used in this study captures those who were at a minimum pre-frail but may have missed identifying some individuals for whom self-reported exhaustion was a factor.

Despite the low prevalence of frailty, its association with falls identified in this study highlights its relevance in terms of clinical assessment of complex obesity. Frailty negatively influences outcomes after both unintentional stressors such as infection (31) and planned interventions such as surgery (32).



Frontiers in Rehabilitation Sciences | www.frontiersin.org 
Identification of patients with frailty would allow for targeted rehabilitation of patients referred for bariatric surgery.

Wang et al. (33) reported mean grip strength across age and gender cohorts, with wide-ranging results, from $18.7 \mathrm{~kg}$ for the non-dominant hand in older women, to $49.7 \mathrm{~kg}$ for the dominant hand in younger men. The age group closest to the WMS cohort were those aged $45-49$ years, who had a mean grip strength of $42.8 \mathrm{~kg} \pm 10.9$ for men and $29.9 \mathrm{~kg} \pm 6.2$ for women. These results are similar to the WMS cohort suggesting that determining muscular endurance rather than static measurement alone may be important in identifying at risk groups.

A further meta-analysis on functional reach reported a mean functional reach of $27.2 \mathrm{~cm}$ in older adults (34). Previously reported data on younger cohorts provides a closer age range for comparison with the WMS population, with those aged between 41 and 69 years achieving a functional reach of $38 \pm 5.6 \mathrm{~cm}$ for men and $26.6 \pm 9 \mathrm{~cm}$ for women (35). The mean functional reach of $37.6 \mathrm{~cm}$ in the WMS population compared well with this.

Bohannon in a meta-analysis of normative values for the five times sit to stand measure reported a mean time of $11.4 \mathrm{~s}$ in adults 60-69 years, $12.6 \mathrm{~s}$ among $70-79$ years and $14.8 \mathrm{~s}$ in participants $80-89$ years (36). Given the mean time for participants in the WMS cohort was $14.0 \mathrm{~s}$, overall performance in this dynamic test was comparable to much older adults.

The TUG is a widely used health outcome measure. The WMS population, with a mean age of $44.2 \pm 11.7$ years, had an average TUG test of $8.6( \pm 14.4)$ s. Normative data published by (37) showed that this value was associated with a population of $60-$ 69 years. By this measure, our population aligns with a group $20+$ years older, reflecting the difficulties experienced by this population with everyday mobility.

This is further reflected in the gait speed data. A meta-analysis of gait speed by Bohannon found that among men and women $40-49$ years a mean of $1.43 \mathrm{~m} / \mathrm{s}(1.3-1.5)$ and $1.4 \mathrm{~m} / \mathrm{s}(1.3-$ 1.4) respectively was achieved (38), compared to $1.1( \pm 0.6)$ for women and $1.1( \pm 0.3)$ for men in the WMS population. The only participants to have slower gait speed than the WMS cohort were men aged $80-99$ years, with a gait speed of $0.97 \mathrm{~m} / \mathrm{sec}(0.83-1.10)$, and women aged $70-77$ years, $1.13 \mathrm{~m} / \mathrm{sec}(1.07-1.19)$ and $80-99$ years, $0.94(0.85-1.03)$.

Falls are often discussed in the context of ageing, and the consideration of age-related reductions in muscle mass and bone mineral density. However, falls present a risk for people of all ages living with obesity. One in three (28.8\%) of WMS patients in this study had a history of falls. The TILDA report on Health and Wellbeing: Active Ageing for Older Adults in Ireland reports a prevalence of $37.3 \%$ of any fall reported in the last year (Matthew O'Connell). Comparison with the TILDA data on individual age groupings highlights that falls rate among the WMS population, whose average age is mid-40's, was equivalent to that in over 50 's within the general population (39).

Metabolic syndrome among TILDA population was reported between 41.6 and $47.3 \%$ depending on the criteria used (40). With substantially higher levels in the WMS population at $55.1 \%$, presence of metabolic syndrome is of concern due to the increased cardiovascular risk and morbidity associated with it (41). Additionally, the association of metabolic syndrome with physical function measures and frailty found in this study, highlights the cross relevance of these measures in this younger population with obesity, and mirrors the association with falls and frailty noted among older adults (13). A pathway of altered body composition, including sarcopenia, leading to reduced physical activity, fitness and functional performance, and eventually resulting in increased risk of metabolic syndrome, reduced Qol and increased risk of falls-related fractures has been outlined in other patient groups, such as those with cancer (42). Sarcopenic obesity with concurrent metabolic syndrome appears to form a similar pathway.

These findings suggest that patients living with complex obesity are performing at a similar level to adults at least a decade their senior. Despite the daily challenges of life experienced by these patients due to this relatively impaired physical functioning, falls risk factors, such as fear of falling, which are routinely considered in older populations $(1,39)$ are not a routine component of obesity assessment. The addition of monitoring for early risk factors for falls to standard clinical assessment of people living with obesity, could improve prevention and management of these conditions, and support independent living.

The Edmonton Obesity Staging System (EOSS) is a widely used (43) five-stage system of obesity classification that utilises metabolic, physical, and psychological parameters to determine optimal obesity treatment. First introduced in 2009 (44) it is a framework for holistic assessment and encompasses the four main health domains: metabolic, mechanical, mental health, and social milieu (the 4Ms). The EOSS considers comorbidity and functional status in predicting mortality. Using such a framework positions the metabolic and mechanical domains in relation to each other so that the relevance of metabolic syndrome in terms of frailty and falls risk in this population is not overlooked. A framework such as this demonstrates how interventions to assess and support physical function can be positioned across these domains to maximise their impact.

The associations seen in this study between frailty and metabolic syndrome in people with obesity adds to the data available on these common concerns in this high-risk population.

While both metabolic health and physical function are considered in the guidance on specialist treatment of complex obesity (22), their cross-discipline relevance, and combined importance are not specifically noted. Frailty and falls are both multifactorial concerns, with several modifiable risk factors that lend themselves to preventative interventions, including physical function and metabolic syndrome. Screening for frailty and falls through utilising grip strength and gait speed in those with obesity and metabolic syndrome could help target therapies aimed at improving strength and physical function. Combined resistance and aerobic exercise have been shown to be effective and safe in attenuating metabolic syndrome and sarcopenic obesity (45) simultaneously addressing the risk of frailty and falls and the metabolic dysregulation of metabolic syndrome.

\section{STUDY LIMITATIONS}

Due to the retrospective nature of our data analysis, we were required to utilise a modified frailty scale. Although the study cohort had a lower mean age than most research available on 
frailty, we feel this may have contributed to an under-estimation of frailty prevalence.

\section{CONCLUSION}

The findings of this study add to the evidence underpinning the importance of a circular health perspective when treating complex obesity, and the benefit of using a holistic assessment approach that incorporates screening of both metabolic and physical function. We recommend that such an approach be employed in the assessment and treatment planning for patients with complex obesity, to facilitate timely and thorough assessment and appropriate treatment of the interconnected concerns of frailty, falls, and metabolic syndrome.

\section{DATA AVAILABILITY STATEMENT}

The raw data supporting the conclusions of this article will be made available by the authors, without undue reservation.

\section{ETHICS STATEMENT}

Ethical review and approval was not required for the study on human participants in accordance with the local legislation

\section{REFERENCES}

1. Lee L, Patel T, Costa A, Bryce E, Hillier LM, Slonim K, et al. Screening for frailty in primary care: accuracy of gait speed and hand-grip strength. Can Fam Physician. (2017) 63:e51-7.

2. Vermeiren S, Vella-Azzopardi R, Beckwée D, Habbig AK, Scafoglieri A, Jansen B, et al. Frailty and the prediction of negative health outcomes: a meta-analysis. J Am Med Dir Assoc. (2016) 17:1163.e116117. doi: 10.1016/j.jamda.2016.09.010

3. O'Halloran A, McGarrigle C, Scarlett S, Roe L, Romero-Ortuno R, Kenny R. TILDA Report on Population Estimates of Physical Frailty in Ireland to Inform Demographics for Over 50s in Ireland during the COVID-19 Pandemic. (2020). Available online at: https://tilda.tcd.ie/publications/reports/ pdf/Report_Covid19Frailty.pdf (accessed April 27, 2021).

4. Landré B, Czernichow S, Goldberg M, Zins M, Ankri J, Herr M. Association between life-course obesity and frailty in older adults: findings in the GAZEL cohort. Obesity. (2020) 28:388-96. doi: 10.1002/oby.22682

5. Buta BJ, Walston JD, Godino JG, Park M, Kalyani RR, Xue QL, et al. Frailty assessment instruments: systematic characterization of the uses and contexts of highly-cited instruments. Ageing Res Rev. (2016) 26:5361. doi: 10.1016/j.arr.2015.12.003

6. Yang F, Munoz J, Han LZ. Effects of vibration training in reducing risk of slip-related falls among young adults with obesity. J Biomech. (2017) 57:87-93. doi: 10.1016/j.jbiomech.2017.03.024

7. O'Connell M, Kenny R, Donoghue O. Health and Wellbeing: Active Ageing for Older Adults in Ireland Evidence from The Irish Longitudinal Study on Ageing. (2019). Available online at: https:/tilda.tcd.ie/publications/reports/ pdf/w3-key-findings-report/Chapter\%206.pdf (accessed April 27, 2021).

8. Beard JR, Officer A, de Carvalho IA, Sadana R, Pot AM, Michel JP, et al. The World report on ageing and health: a policy framework for healthy ageing. Lancet. (2016) 387:2145-2154. doi: 10.1016/S0140-6736(15)0 0516-4

9. Heinrich S, Rapp K, Rissmann U, Becker C, König HH. Cost of falls in old age: a systematic review. Osteoporos Int. (2010) 21:891902. doi: 10.1007/s00198-009-1100-1 and institutional requirements. Written informed consent for participation was not required for this study in accordance with the national legislation and the institutional requirements.

\section{AUTHOR CONTRIBUTIONS}

AR and EO'M: conceived and designed the study and performed the literature review. EO'M and $\mathrm{CD}$ : designed the database and conducted the data collection. AR: performed all statistical analysis, provided structure to the initial draught, and contributed to subsequent iterations. EO'M: wrote sections of the manuscript, guided the clinical direction of research findings, and contributed to manuscript editing and formatting. $\mathrm{KH}$ and $\mathrm{CD}$ : reviewed and edited draughts and providing expertise on physical function. JO'C and DO'S: reviewed and edited draughts providing guidance from a medical perspective. All authors contributed to the article, agree to be accountable for the content, and approved the submitted version.

\section{ACKNOWLEDGMENTS}

We would like to thank the contribution of the patients of the weight management service who kindly consent to the utilisation of their data and our colleagues who support our ongoing research in obesity.

10. Peeters G, van Schoor NM, Cooper R, Tooth L, Kenny RA. Should prevention of falls start earlier? Co-ordinated analyses of harmonised data on falls in middle-aged adults across four population-based cohort studies. PLoS ONE. (2018) 13:e0201989. doi: 10.1371/journal.pone.0201989

11. Alexandre TDS, Aubertin-Leheudre M, Carvalho LP, Máximo RO, Corona LP, Brito TRP, et al. Dynapenic obesity as an associated factor to lipid and glucose metabolism disorders and metabolic syndrome in older adults - findings from SABE Study. Clin Nutr. (2018) 37:1360-6. doi: 10.1016/j.clnu.2017.06.009

12. Liao $\mathrm{KC}, \mathrm{Pu} \mathrm{SJ}$, Lin $\mathrm{CH}$, Chang $\mathrm{HJ}$, Chen YJ, Liu MS. Association between the metabolic syndrome and its components with falls in community-dwelling older adults. Metab Syndr Relat Disord. (2012) 10:44751. doi: 10.1089/met.2012.0046

13. Teoh RJJ, Mat S, Khor HM, Kamaruzzaman SB, Tan MP. Falls, frailty, and metabolic syndrome in urban dwellers aged 55 years and over in the Malaysian elders longitudinal research (MELoR) study - a cross-sectional Study. Postgrad Med. (2020) 2020:1-6. doi: 10.1080/00325481.2020.1842026

14. Máximo RO, Santos JLF, Perracini MR, Oliveira C, Duarte YAO, Alexandre TDS. Abdominal obesity, dynapenia and dynapenic-abdominal obesity as factors associated with falls. Braz J Phys Ther. (2019) 23:497505. doi: 10.1016/j.bjpt.2018.10.009

15. do Nascimento JA, Silva CC, Dos Santos HH, de Almeida Ferreira JJ, de Andrade PR. A preliminary study of static and dynamic balance in sedentary obese young adults: the relationship between BMI, posture and postural balance. Clin Obes. (2017) 7:377-83. doi: 10.1111/cob.12209

16. Follis S, Cook A, Bea JW, Going SB, Laddu D, Cauley JA, et al. Association between sarcopenic obesity and falls in a multiethnic cohort of postmenopausal women. J Am Geriatr Soc. (2018) 66:2314-20. doi: 10.1111/jgs.15613

17. Collins KH, Herzog W, MacDonald GZ, Reimer RA, Rios JL, Smith IC, et al. Obesity, metabolic syndrome, and musculoskeletal disease: common inflammatory pathways suggest a central role for loss of muscle integrity. Front Physiol. (2018) 9:112. doi: 10.3389/fphys.2018.00112

18. Riebe D, Blissmer BJ, Greaney ML, Garber CE, Lees FD, Clark PG. The relationship between obesity, physical activity, and physical function in older adults. J Aging Health. (2009) 21:1159-78. doi: 10.1177/0898264309350076 
19. Jurca R, Lamonte MJ, Barlow CE, Kampert JB, Church TS, Blair SN. Association of muscular strength with incidence of metabolic syndrome in men. Med Sci Sports Exerc. (2005) 37:1849-55. doi: 10.1249/01.mss.0000175865.17614.74

20. Nathan BM, Moran A. Metabolic complications of obesity in childhood and adolescence: more than just diabetes. Curr Opin Endocrinol Diabetes Obes. (2008) 15:21-9. doi: 10.1097/MED.0b013e3282f43d19

21. Vikram NK. Cardiovascular and metabolic complications - diagnosis and management in obese children. Indian J Pediatr. (2018) 85:53545. doi: 10.1007/s12098-017-2504-0

22. Welbourn R, Hopkins J, Dixon JB, Finer N, Hughes C, Viner R, et al. Commissioning guidance for weight assessment and management in adults and children with severe complex obesity. Obes Rev. (2018) 19:1427. doi: 10.1111/obr.12601

23. Auyeung TW, Lee JS, Leung J, Kwok T, Woo J. The selection of a screening test for frailty identification in community-dwelling older adults. J Nutr Health Aging. (2014) 18:199-203. doi: 10.1007/s12603-013-0365-4

24. MacDermid J, Solomon G, Valdes K. Clinical Assessment Recommendations. 3rd ed. Mount Laurel, NJ: American Society of Hand Therapists (2015).

25. Podsiadlo D, Richardson S. The timed "Up \& Go": a test of basic functional mobility for frail elderly persons. J Am Geriatr Soc. (1991) 39:1428. doi: 10.1111/j.1532-5415.1991.tb01616.x

26. The International Diabetes Federation. The IDF Consensus Worldwide Definition of the Metabolic Syndrome. Available online at: https://www.idf.org/ e-library/consensus-statements/60-idfconsensus-worldwide-definitionofthe-metabolic-syndrome.html (accessed March 29, 2021).

27. Wharton S, Lau D, Vallis M, Sharma A, Biertho L, Campbell-Scherer D, et al. Obesity in adults: a clinical practice guideline. MAJ. (2020) 92:E87591. doi: 10.1503/cmaj.191707

28. Ross R, Neeland IJ, Yamashita S, Shai I, Seidell J, Magni P, et al. Waist circumference as a vital sign in clinical practice: a Consensus Statement from the IAS and ICCR Working Group on Visceral Obesity. Nat Rev Endocrinol. (2020) 16:177-89. doi: 10.1038/s41574-019-0310-7

29. Kehler DS, Ferguson T, Stammers AN, Bohm C, Arora RC, Duhamel TA, et al. Prevalence of frailty in Canadians 18-79 years old in the Canadian Health Measures Survey. BMC Geriatr. (2017) 17:28. doi: 10.1186/s12877-0170423-6

30. Turner G, Clegg A, Society BGUKA, Practioners RCoG. Best practice guidelines for the management of frailty: a British Geriatrics Society, Age UK and Royal College of General Practitioners report. Age Ageing. (2014) 43:744-7. doi: 10.1093/ageing/ afu 138

31. Lees C, Godin J, McElhaney JE, McNeil SA, Loeb M, Hatchette TF, et al. Frailty hinders recovery from influenza and acute respiratory illness in older adults. $J$ Infect Dis. (2020) 222:428-37. doi: 10.1093/infdis/jiaa092

32. Muscedere J, Waters B, Varambally A, Bagshaw SM, Boyd JG, Maslove $\mathrm{D}$, et al. The impact of frailty on intensive care unit outcomes: a systematic review and meta-analysis. Intensive Care Med. (2017) 43:110522. doi: 10.1007/s00134-017-4867-0

33. Wang YC, Bohannon RW, Li X, Sindhu B, Kapellusch J. Hand-grip strength: normative reference values and equations for individuals 18 to 85 years of age residing in the United States. J Orthop Sports Phys Ther. (2018) 48:68593. doi: 10.2519/jospt.2018.7851

34. Bohannon RW, Wolfson LI, White WB. Functional reach of older adults: normative reference values based on new and published data. Physiotherapy. (2017) 103:387-91. doi: 10.1016/j.physio.2017. 03.006
35. Duncan PW, Weiner DK, Chandler J, Studenski S. Functional reach: a new clinical measure of balance. J Gerontol. (1990) 45:M192-197. doi: 10.1093/geronj/45.6.M192

36. Bohannon RW. Reference values for the five-repetition sit-to-stand test: a descriptive meta-analysis of data from elders. Percept Mot Skills. (2006) 103:215-22. doi: 10.2466/pms.103.1.215-222

37. Bohannon RW. Reference values for the timed up and go test: a descriptive meta-analysis. $J$ Geriatr Phys Ther. (2006) 29:64-8. doi: 10.1519/00139143-200608000-00004

38. Bohannon RW, Williams Andrews A. Normal walking speed: a descriptive meta-analysis. Physiotherapy. (2011) 97:1829. doi: 10.1016/j.physio.2010.12.004

39. O'Connell M, Kenny RA, Donoghue O. Health and Wellbeing: Active Ageing for Older Adults in Ireland Evidence from The Irish Longitudinal Study on Ageing. (2020). Available online at: https://tilda.tcd.ie/publications/reports/ pdf/w3-key-findings-report/Chapter\%206.pdf (accessed April 27, 2021).

40. O'Connor D, Leahy S, McGarrigle C, Kenny R. A comparison of the prevalence of IDF- and ATPIII- defined metabolic syndrome in adults aged 50 and over in Ireland: findings from TILDA. Proc Nutr Soc. (2016) 75:E209. doi: 10.1017/S002966511600224X

41. Alshehri AM. Metabolic syndrome and cardiovascular risk. J Family Community Med. (2010) 17:73-8. doi: 10.4103/1319-1683.71987

42. Keogh JW, MacLeod RD. Body composition, physical fitness, functional performance, quality of life, and fatigue benefits of exercise for prostate cancer patients: a systematic review. J Pain Symptom Manage. (2012) 43:96110. doi: 10.1016/j.jpainsymman.2011.03.006

43. Atlantis E, Sahebolamri M, Cheema BS, Williams K. Usefulness of the Edmonton Obesity Staging System for stratifying the presence and severity of weight-related health problems in clinical and community settings: a rapid review of observational studies. Obes Rev. (2020) 21:e13120. doi: 10.1111/obr.13120

44. Sharma AM, Kushner RF. A proposed clinical staging system for obesity. Int $J$ Obes. (2009) 33:289-95. doi: 10.1038/ijo.2009.2

45. Dieli-Conwright CM, Courneya KS, Demark-Wahnefried W, Sami N, Lee K, Buchanan TA, et al. Effects of aerobic and resistance exercise on metabolic syndrome, sarcopenic obesity, and circulating biomarkers in overweight or obese survivors of breast cancer: a randomized controlled trial. J Clin Oncol. (2018) 36:875-83. doi: 10.1200/JCO.2017.75.7526

Conflict of Interest: The authors declare that the research was conducted in the absence of any commercial or financial relationships that could be construed as a potential conflict of interest.

Publisher's Note: All claims expressed in this article are solely those of the authors and do not necessarily represent those of their affiliated organizations, or those of the publisher, the editors and the reviewers. Any product that may be evaluated in this article, or claim that may be made by its manufacturer, is not guaranteed or endorsed by the publisher.

Copyright (C) 2021 Rhynehart, Dunlevy, Hayes, O'Connell, O'Shea and O'Malley. This is an open-access article distributed under the terms of the Creative Commons Attribution License (CC BY). The use, distribution or reproduction in other forums is permitted, provided the original author(s) and the copyright owner(s) are credited and that the original publication in this journal is cited, in accordance with accepted academic practice. No use, distribution or reproduction is permitted which does not comply with these terms. 